Jun Ying*, Hai-Chen Mou, Jia-Ni Liu, Gui-Ying Liu, Xue-Bin Ji, Ting-Ting Li and Ai-Xiang Tian*

\title{
A series of Keggin- and Wells-Dawson- polyoxometalate-based compounds constructed from oxygen-functional imidazole derivatives
}

https://doi.org/10.1515/znb-2018-0067

Received March 20, 2018; accepted June 5, 2018

Abstract: Through the use of two kinds of imidazole derivatives containing different $\mathrm{O}$-functional units, three new Keggin- and one Wells-Dawson-polyoxometalate (POM)based compounds, namely $\left[\mathrm{Cu}_{2} \mathbf{L}_{4}{ }_{4}\left(\mathrm{HPW}_{12} \mathrm{O}_{40}\right)\right](\mathbf{1}),\left[\mathrm{CuL}^{\mathrm{a}}\right.$ $\left.{ }_{4}\left(\mathrm{H}_{2} \mathrm{O}\right)_{2}\left(\mathrm{HPMo}_{12} \mathrm{O}_{40}\right)\right]$ (2), $\left[\mathrm{Cu}_{2} \mathbf{L}_{7}^{\mathrm{a}}\left(\mathrm{H}_{2} \mathrm{O}\right)\left(\mathrm{H}_{2} \mathrm{P}_{2} \mathrm{~W}_{18} \mathrm{O}_{62}\right)\right] \cdot \mathbf{L} \mathbf{a}(\mathbf{3})$, $\left[\mathrm{Ag}_{2}\left(\mathbf{L}_{4}^{\mathbf{b}}\right)\left(\mathrm{HPMo}_{12} \mathrm{O}_{40}\right)\right] \cdot \mathbf{L}^{\mathbf{b}} \cdot \mathrm{H}_{2} \mathrm{O} \quad(\mathbf{4})\left(\mathbf{L}^{\mathbf{a}}=\right.$ (4-(2,5-dihydro$1 H$-imidazol-1-yl)benzaldehyde), and $\mathbf{L}^{\mathbf{b}}=(4-(2,5$-dihydro$1 H$-imidazol-1-yl)benzoic acid), were synthesized and characterized using single-crystal X-ray diffraction, elemental analyses, and infrared spectroscopy. The polyoxoanions occupy holes framed by two symmetrically oriented $\mathrm{CuL}^{\mathrm{a}}{ }_{2}$ units in 1. In compound 2, the squareplanar $\mathrm{CuL}_{4}{ }_{4}$ units form a two-dimensional (2D), supramolecular grid through $\pi \cdots \pi$ stacking interactions. The POMs occupy vacancies in this grid. In compound $\mathbf{3}$, the $\mathrm{CuL}_{3}{ }_{3}$ subunits connect the neighboring $\mathrm{P}_{2} \mathrm{~W}_{18}$ units and an " $\mathrm{S}$ "-type chain is formed. Through hydrogen bonding interactions, the chains are connected to form a layer. In compound 4, the POM anions are linked by $\mathrm{AgL}^{\mathrm{b}}{ }_{2}$ subunits to form a chain. All the chains are tied together to construct a layer structure with weak hydrogen bonding interactions between the terminal carboxylic acid functional groups of ligands $\mathbf{L}^{\mathbf{b}}$. The electrocatalytic and photocatalytic activities of all these four compounds were also studied.

Keywords: 4-(2,5-dihydro-1H-imidazol-1-yl)benzaldehyde; 4-(2,5-dihydro-1H-imidazol-1-yl)benzoic acid; electrochemical properties; photocatalytic properties; polyoxometalate (POM).

\footnotetext{
*Corresponding authors: Jun Ying, and Ai-Xiang Tian, Department of Chemistry, Bohai University, Jinzhou 121013, PR China, e-mail: ying@bhu.edu.cn (J. Ying); tian@bhu.edu.cn (A.-X. Tian) Hai-Chen Mou, Jia-Ni Liu, Xue-Bin Ji and Ting-Ting Li: Department of Chemistry, Bohai University, Jinzhou 121013, PR China Gui-Ying Liu: Liaoning Ocean and Fisheries Science Research Institute, Dalian, PR China
}

\section{Introduction}

Polyoxometalates (POMs), as transition-metal oxide anionic clusters, possess abundant structural features [1] and versatile properties [2], including catalysis, photochemical, and electrochemical activity [3, 4]. Thus, POMs have played a role as excellent inorganic building blocks for constructing POM-based compounds, particularly, in building high-dimensional [5] and novel topological structures [6-8]. So far, because of their structural diversities and potential applications as functional materials, the design and assembly of organicinorganic hybrid polymers has become an area of rapid growth. Among all the types of POMs, Keggin- and Wells-Dawson are viewed as the most classical anions. They have abundant terminal and bridging $\mathrm{O}$ atoms and exhibit strong coordination abilities which enable them to form transition metal complexes efficiently.However, the choice of appropriate organic ligands is extremely important in the self-assembly process of the prospective Keggin- and Wells-Dawson-based transition metal complexes $[9,10]$. The POM-based hybrids can be constructed using either rigid or flexible N-heterocyclic ligands [11, 12]. The flexible ligands can give rise to complicated and unpredictable POM-based structures owing to their conformational flexibility. In contrast, the rigid ligands are more conducive to the targeted synthesis of the POM-based compounds [6, 13]. Some rigid ligands with simple coordination modes were introduced to the POMs initially, such as, 1,10-phenanthroline, 2,2'- and 4,4'-bipy and imidazole [14, 15]. In this work, we chose derivatives of imidazole as organic moieties, which own strong coordination capacity. Up to now, organic ligands containing mixed N/O donors were rarely used in POM field. For example, pyridine-carboxylic acid and bis-pyridyl-bis-amide ligands were commonly used $[16,17]$. The additional $\mathrm{O}$ donor cannot only coordinate with the transition metals, but also act as supramolecular synthon to support the hydrogen bonding interactions. Thus, in this work, we used mixed N/Ocontaining imidazole derivatives to modify the POMs, namely, (4-(2,5-dihydro-1H-imidazol-1-yl)benzaldehyde) 


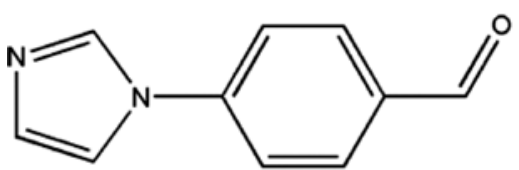

$\mathbf{L}^{\mathbf{a}}$

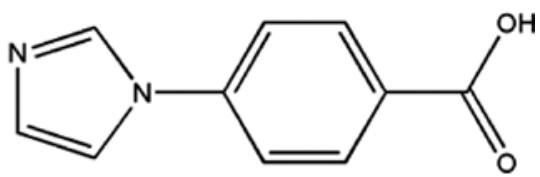

$\mathbf{L}^{\mathrm{b}}$

Scheme 1: The ligands 4-(2,5-dihydro-1H-imidazol-1-yl)benzaldehyde ( $\left.\mathbf{L}^{\mathrm{a}}\right)$, and 4-(2,5-dihydro- $1 \mathrm{H}$-imidazol-1-yl)benzoic acid ( $\left.\mathbf{L}^{\mathrm{b}}\right)$.

( $\left.\mathbf{L}^{\mathrm{a}}\right)$ and (4-(2,5-dihydro-1 $H$-imidazol-1-yl)benzoic acid) $\left(\mathbf{L}^{\mathbf{b}}\right)$ (Scheme 1), in order to exert double functions of $\mathrm{N}$ and $\mathrm{O}$ donors.

In this work, by using $\mathbf{L}^{\mathrm{a}}$ and $\mathbf{L}^{\mathrm{b}}$, we have synthesized four supramolecular compounds under hydrothermal conditions, $\left[\mathrm{Cu}_{2} \mathrm{~L}_{4}^{\mathrm{a}}\left(\mathrm{HPW}_{12} \mathrm{O}_{40}\right)\right](\mathbf{1}),\left[\mathrm{CuL}_{4}^{\mathrm{a}}\left(\mathrm{H}_{2} \mathrm{O}\right)_{2}\left(\mathrm{HPMo}_{12} \mathrm{O}_{40}\right)\right]$ (2), $\left[\mathrm{Cu}_{2} \mathbf{L}_{7}^{\mathbf{a}}\left(\mathrm{H}_{2} \mathrm{O}\right)\left(\mathrm{H}_{2} \mathrm{P}_{2} \mathrm{~W}_{18} \mathrm{O}_{62}\right)\right] \cdot \mathbf{L}^{\mathbf{a}}(\mathbf{3}),\left[\mathrm{Ag}_{2}\left(\mathbf{L}_{4}^{\mathbf{b}}\right)\left(\mathrm{HPMO}_{12} \mathrm{O}_{40}\right)\right] \cdot$ $\mathbf{L}^{\mathbf{b}} \cdot \mathrm{H}_{2} \mathrm{O}$ (4). Furthermore, the electrochemical and photocatalytic properties of these compounds were reported.

\section{Results and discussion}

\subsection{Structure description}

In this article, we present four compounds based on different POM anions and transition metal ions with two kinds of ligands. In the system of $\mathbf{L}^{\mathbf{a}}$, the Keggin-based compound $\mathbf{1}$ was obtained by capturing $\mathrm{Cu}^{+}$. In the $\mathrm{Cu}^{2+} / \mathbf{L}^{\mathrm{a}}$ system, different Keggin- and Wells-Dawson anions induce distinct structures of $\mathbf{2}$ and 3. Compound $\mathbf{2}$ is a discrete structure, but compound $\mathbf{3}$ shows a chain. When the $\mathbf{L}^{\mathbf{b}}$ ligand was used instead of $\mathbf{L}^{\mathbf{a}}$ in $\mathbf{1}$ of the Keggin $/ \mathbf{L}^{\mathbf{a}}$ system, a different chain of $\mathbf{4}$ was formed. Thus, under hydrothermal conditions, the reactants exhibit obvious influences on the structures [18] (Table 1).

\subsection{1 $\left[\mathrm{Cu}_{2} \mathrm{~L}_{4}^{\mathrm{a}}\left(\mathrm{HPW}_{12} \mathrm{O}_{40}\right)\right](1)$}

The crystal structure determination reveals that compound 1 consists of two $\mathrm{Cu}^{1}$ ions, four $\mathbf{L}^{\mathrm{a}}$ ligands, and one $\left[\mathrm{PW}_{12} \mathrm{O}_{40}\right]^{3-}\left(\right.$ abbreviated to $\mathrm{PW}_{12}$ ) anion (Fig. 1). The valence sum calculations [19] show that all the $\mathrm{W}$ atoms are in the $+\mathrm{VI}$ oxidation state, and all the $\mathrm{Cu}$ atoms are in the $+\mathrm{I}$ oxidation state.

In compound 1, there is only one crystallographically independent $\mathrm{Cu}^{1}$ ion. Around the $\mathrm{Cu} 1$ atom, the

Table 1: The synthetic scheme of compounds 1-4.

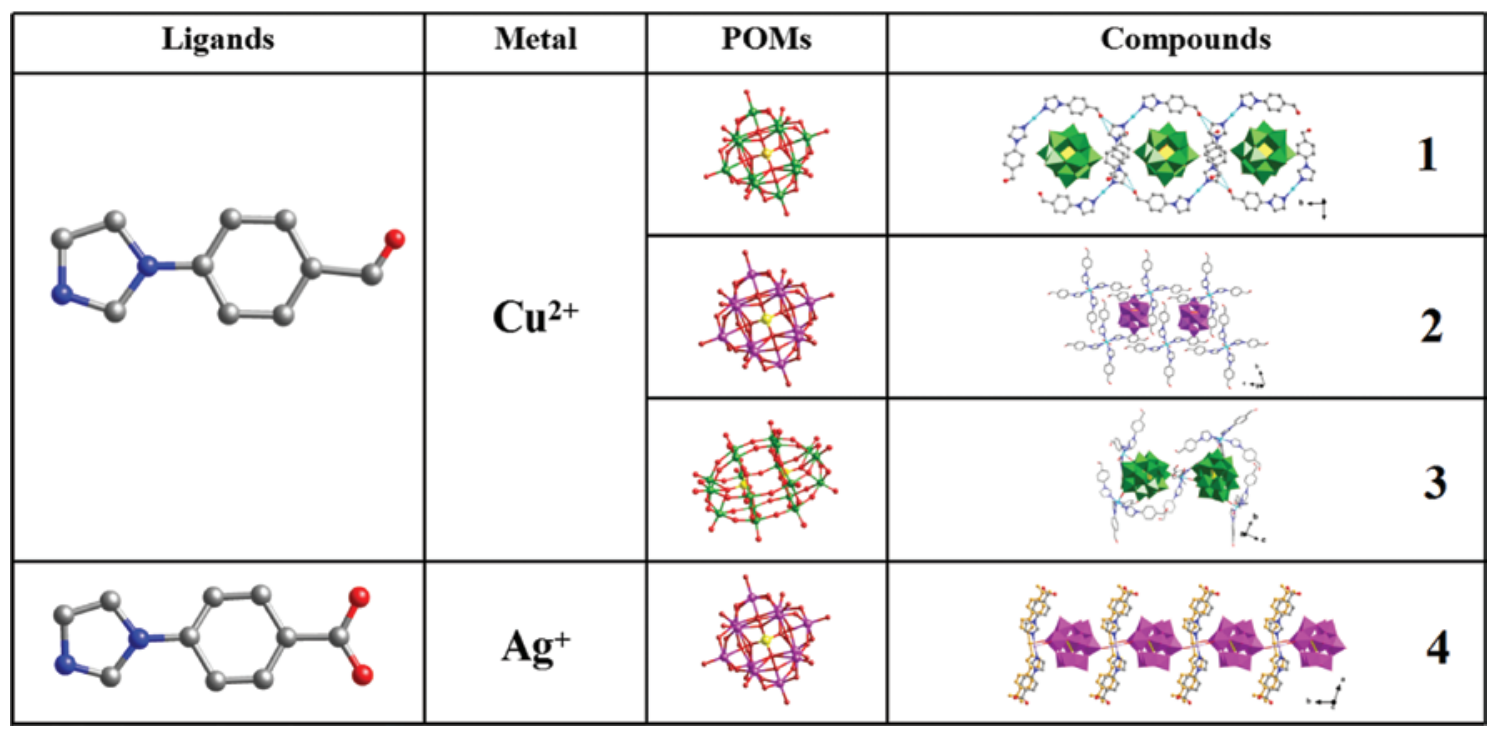




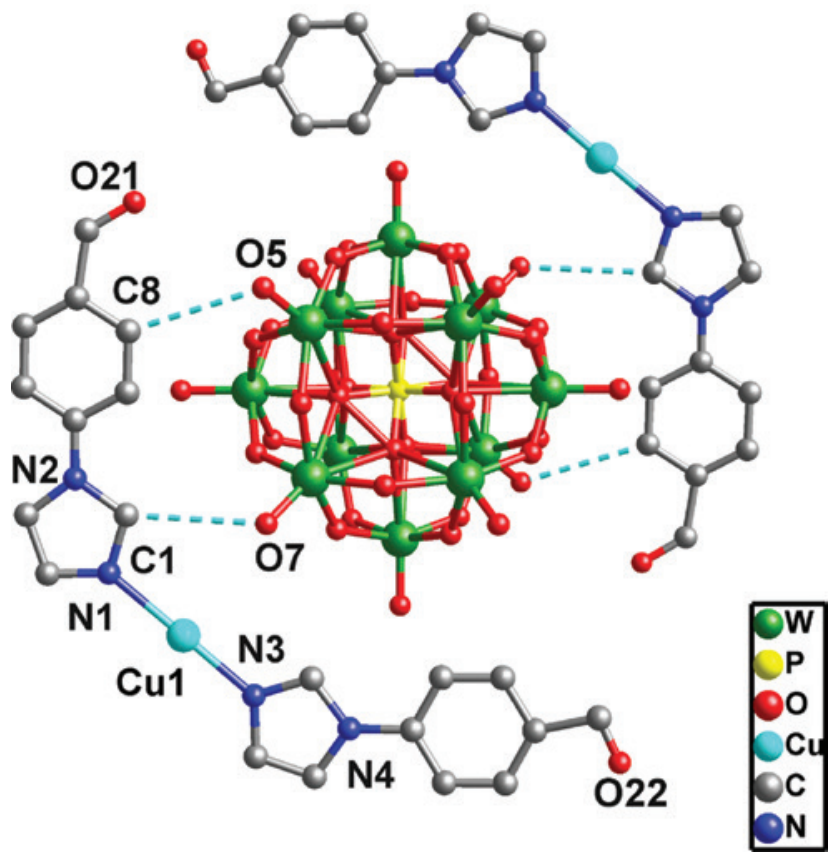

Fig. 1: Ball-and-stick view of the asymmetric unit of 1. The hydrogen atoms are omitted for clarity.

bond distances for $\mathrm{Cu}-\mathrm{N}$ are 2.13(3) and 2.25(2) $\AA$. The $\mathrm{N}-\mathrm{Cu}-\mathrm{N}$ angle is $179.0(16)^{\circ}$ (Table S1; Supporting information available online). In compound $\mathbf{1}$, two $\mathbf{L}^{\mathrm{a}}$ ligands use their two apical $\mathrm{N}$ atoms to chelate one $\mathrm{Cu} 1$ ion to form a metal-organic unit $\left.\left[\mathrm{CuL}_{2}\right]^{\mathbf{a}}\right]^{+}$. Two symmetrical $\left[\mathrm{CuL}_{2}^{\mathrm{a}}\right]^{+}$units button up to shape a hole with the $\mathrm{PW}_{12}$ anion fixed in the center of the hole through hydrogen bonding interactions, such as $\mathrm{C} 8-\mathrm{H} 8 \cdots \mathrm{O} 5=3.292(3)$ $\AA$, C1-H1 $\cdots \mathrm{O} 7=3.395(4) \AA$ (Table S2; supporting information). Adjacent $\mathrm{PW}_{12}$ anions covered with two
$\left[\mathrm{CuL}^{\mathrm{a}}{ }_{2}\right]^{+}$units connect each other through hydrogen bonding interactions [C10-H10 $\cdots \mathrm{O} 16=3.337(3) \AA$ A , C12$\mathrm{H} 12 \cdots \mathrm{O} 21=2.554(4) \AA$; Table S2] to form a supramolecular chain (Fig. 2). All the chains are further linked by $\mathrm{C}$... O interactions to construct a honeycomb-like layer (Fig. S1; supporting information).

\subsection{2 $\left[\mathrm{CuL}_{4}^{\mathrm{a}}\left(\mathrm{H}_{2} \mathrm{O}\right)_{2}\left(\mathrm{HPMo}_{12} \mathrm{O}_{40}\right)\right](2)$}

The structure determination shows that $\mathbf{2}$ consists of one $\mathrm{Cu}^{\mathrm{II}}$ ion, four coordinated $\mathbf{L}^{\mathrm{a}}$ ligands, two coordinated water molecules, and one $\left[\mathrm{PMo}_{12} \mathrm{O}_{40}\right]^{3-}$ (abbreviated to $\mathrm{PMo}_{12}$ ) anion (Fig. 3). The valence sum calculations [19] show that all the Mo atoms are in the +VI oxidation state, and all the $\mathrm{Cu}$ atoms are in the oxidation state $+\mathrm{II}$.

In compound $\mathbf{2}$, there is only one crystallographically independent $\mathrm{Cu}^{\mathrm{II}}$ ion, having an octahedral coordination geometry. The Cu1 ion is six-coordinated by four N (two N1 and two N3) atoms from four $\mathbf{L}^{\mathrm{a}}$ ligands and two $\mathrm{O}$ atoms from two water molecules $\mathrm{O} 2 \mathrm{~W}$. Around the $\mathrm{Cu} 1 \mathrm{atom}$, the $\mathrm{Cu}-\mathrm{N}$ distances are 1.997(4) and 2.015(4) $\AA$. The N-Cu-N angles are $180,89.97(16)$, and $90.03(16)^{\circ}$ (Table S1; supporting information). In compound $\mathbf{2}$, the $\left[\mathrm{CuL}_{4}^{\mathrm{a}}{ }_{4}\right]$ subunit is a crisscross unit with four $\mathbf{L}^{a}$ ligands coordinated by one $\mathrm{Cu}^{\text {II }}$ ion. The crisscross metal-organic units assemble by $\pi \cdots \pi$ stacking interactions [C14 $\cdots \mathrm{C} 17=3.803(2)$ $\AA, \mathrm{C} 15 \cdots \mathrm{C} 18=3.815(2) \AA, \mathrm{C} 16 \cdots \mathrm{C} 19=3.781(2) \AA$, and $\mathrm{C} 13 \cdots \mathrm{C} 20=3.610(2) \AA]$ to form a line (Fig. 4a). Adjacent two lines interpenetrate each other also through $\pi \cdots \pi$ stacking interactions and a grid-like chain is formed (Fig. 4b). The $\mathrm{PMo}_{12}$ unit lies in the grids (Fig. 4c). Furthermore, the $\pi \cdots \pi$ stacking interactions between the chains induce a supramolecular layer of 2, with $\mathrm{PMo}_{12}$ units

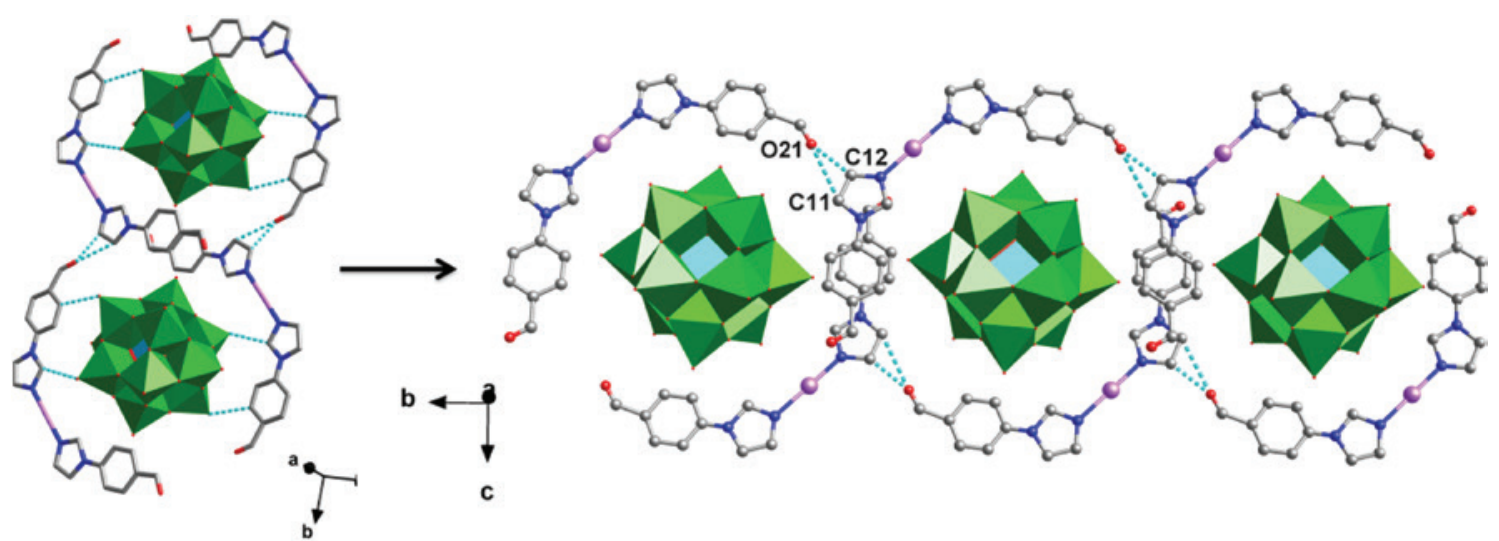

(a)

(b)

Fig. 2: The fragment (a) and the whole supramolecular chain (b) of 1. 


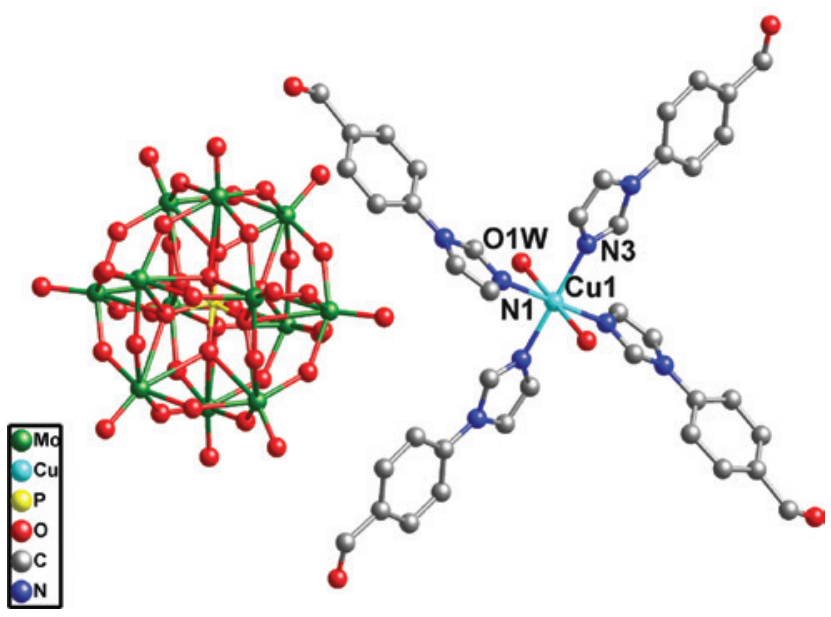

Fig. 3: Ball-and-stick view of the symmetric unit of 2. The hydrogen atoms and water molecules are omitted for clarity.

inserted into the grids, as is shown in Fig. S2 (supporting information).

\subsection{3 $\left[\mathrm{Cu}_{2} \mathrm{~L}_{7}^{\mathrm{a}}\left(\mathrm{H}_{2} \mathrm{O}\right)\left(\mathrm{H}_{2} \mathrm{P}_{2} \mathrm{~W}_{18} \mathrm{O}_{62}\right)\right] \cdot \mathrm{L}^{\mathrm{a}}(3)$}

Compound 3 consists of two $\mathrm{Cu}^{\mathrm{II}}$ ions, seven-coordinated ligands $\mathbf{L}^{\mathbf{a}}$ and one uncoordinated molecule $\mathbf{L}^{\mathbf{a}}$, one-coordinated water molecule, and one $\left[\mathrm{P}_{2} \mathrm{~W}_{18} \mathrm{O}_{62}\right]^{6-}$ (abbreviated to $\mathrm{P}_{2} \mathrm{~W}_{18}$ ) anion (Fig. 5). The valence sum calculations [19] show that all the $\mathrm{W}$ atoms are in the $+\mathrm{VI}$ oxidation state, while the $\mathrm{Cu}$ atoms are in the oxidation state +II.

In 3, there are two kinds of crystallographically independent $\mathrm{Cu}^{\mathrm{II}}$ ions. The $\mathrm{Cu} 1$ ion is five-coordinated by four $\mathrm{N}(\mathrm{N} 1, \mathrm{~N} 3, \mathrm{~N} 5, \mathrm{~N} 7)$ atoms from four $\mathbf{L}^{\mathbf{a}}$ and one $\mathrm{O} 12$ from one $\mathrm{P}_{2} \mathrm{~W}_{18}$ anion. Around the $\mathrm{Cu} 1$ atom, the $\mathrm{Cu}-\mathrm{N}$ distances are 2.010(12), 2.014(11), 1.987(13), 1.988(13) $\AA$, and the $\mathrm{Cu}-\mathrm{O}$ distance is 2.400(9) $\AA$. The $\mathrm{N}-\mathrm{Cu}-\mathrm{O}$ angles are in the range of 80.9(4) $-110.9(4)^{\circ}$ (TableS1; supporting information). The $\mathrm{Cu} 2$ ion is six-coordinated by three $\mathrm{N}(\mathrm{N} 9, \mathrm{~N} 11, \mathrm{~N} 13)$ atoms from three $\mathbf{L}^{\mathbf{a}}$, two $\mathrm{O}$ atoms (010 and $\mathrm{O62}$ ) from two anions, and one coordinated water O1W. Around the Cu2 atom, the $\mathrm{Cu}-\mathrm{N}$ distances are 1.989(10), 2.004(12), and 1.963(10) $\AA$, and the $\mathrm{Cu}-\mathrm{O}$ distance is 2.305(9) $\AA$. The $\mathrm{N}-\mathrm{Cu}-\mathrm{O}$ angles are in the range of 88.0(4)-98.6(4) ${ }^{\circ}$ (Table S1).

In $\mathbf{3}$, the Cu1 cation combines four $\mathbf{L}^{\mathrm{a}}$ ligands to construct a windmill-like subunit $\left[\mathrm{CuL}^{\mathrm{a}}{ }_{4}\right]^{2+}$, while the $\mathrm{Cu} 2$ cation coordinates three ligands and one water molecule to form a $\left[\mathrm{CuL}_{3}{ }_{3}\left(\mathrm{H}_{2} \mathrm{O}\right)\right]^{2+}$ subunit. The $\left[\mathrm{CuL}^{\mathrm{a}}{ }_{3}\left(\mathrm{H}_{2} \mathrm{O}\right)\right]^{2+}$ subunits connect the neighboring $\mathrm{P}_{2} \mathrm{~W}_{18}$ anions to form an " $\mathrm{S}$ " type chain as show in Fig. 6a. However, the $\left[\mathrm{CuL}_{4}^{\mathrm{a}}{ }_{4}{ }^{2+}\right.$ unit containing four $\mathbf{L}^{a}$ ligands may cause bigger steric hindrance compared with $\left[\mathrm{CuL}_{{ }_{3}}{ }_{3}\left(\mathrm{H}_{2} \mathrm{O}\right)\right]^{2+}$. So, the $\left[\mathrm{CuL}_{4}{ }_{4}\right]^{2+}$ unit does not play the extension role, but only acts as the supporting unit for $\mathrm{P}_{2} \mathrm{~W}_{18}$. Furthermore, owing to the hydrogen bonding interactions, the "S"-type chains are interconnected to construct a pane-like layer with the $\mathrm{P}_{2} \mathrm{~W}_{18}$ units embedded in the pane, as is shown in Fig. $6 \mathrm{~b}$ and c.

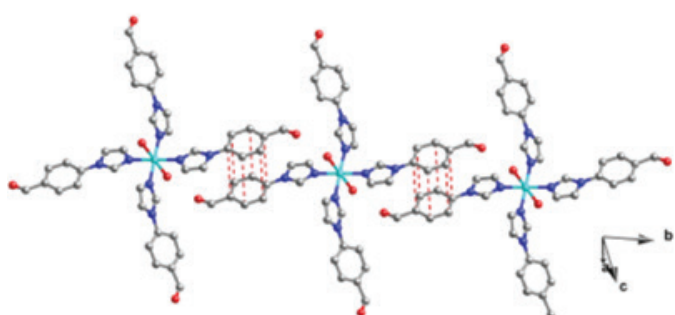

(a)

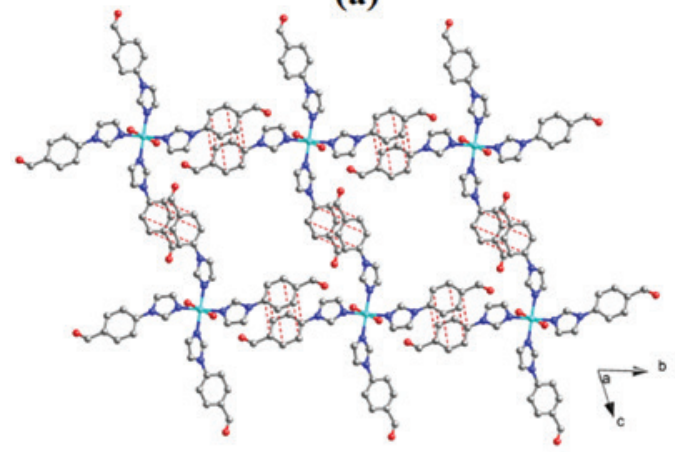

(b)

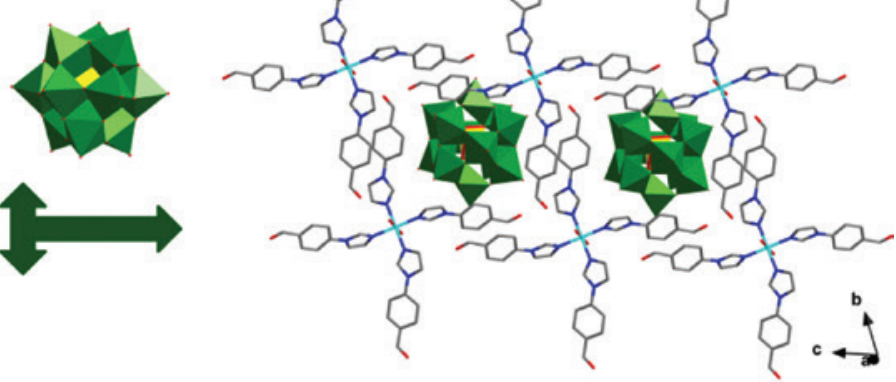

(c)

Fig. 4: (a) The supramolecular array of 2. (b) The supramolecular chain with anions inserted into the grid (c). 


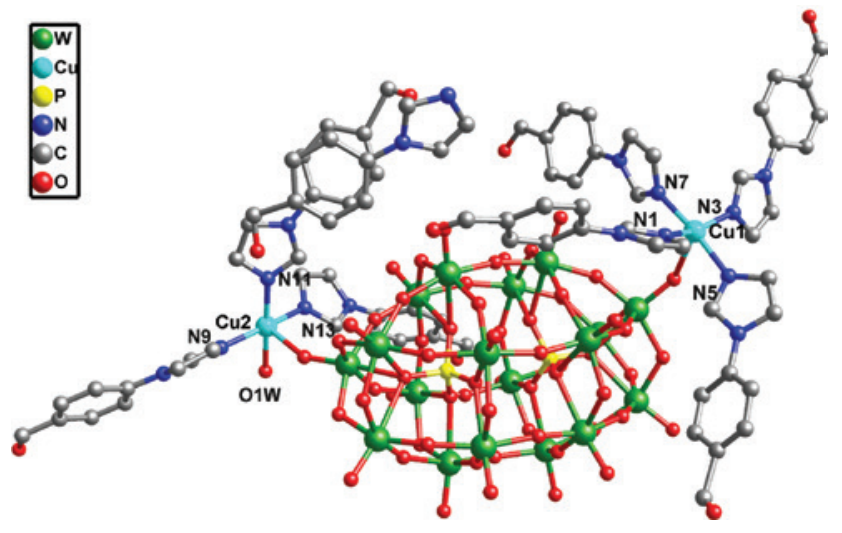

Fig. 5: Ball-and-stick view of the asymmetric unit of 3. The hydrogen atoms are omitted for clarity.

\subsection{4 $\left[\mathrm{Ag}_{2}\left(\mathrm{LL}_{4}^{\mathrm{b}}\right)\left(\mathrm{HPMo}_{12} \mathrm{O}_{40}\right)\right] \cdot \mathrm{Lb}^{\mathrm{b}} \cdot \mathrm{H}_{2} \mathrm{O}(4)$}

In crystals of 4 there are two $\mathrm{Ag}^{\mathrm{I}}$ ions, four-coordinated and one dissociative $\mathbf{L}^{\mathbf{b}}$ ligands, one crystal water molecule, and one $\mathrm{PMo}_{12}$ anion (Fig. 7). The valence sum calculations [19] show that all the Mo atoms are in the $+\mathrm{VI}$ oxidation state, all $\mathrm{Ag}$ atoms are in the oxidation state $+\mathrm{I}$.

In 4, there is one kind of crystallographically independent $\mathrm{Ag}^{\mathrm{I}}$ ions. The $\mathrm{Ag} 1$ ion is three-coordinated by two $\mathrm{N}$ atoms (N1, N3) from two $\mathbf{L}^{\mathbf{b}}$ and one $\mathrm{O} 6$ atom from one $\mathrm{PMo}_{12}$ anion. Around the $\mathrm{Ag} 1$ atom, the $\mathrm{Ag}-\mathrm{N}$ distances are 2.096(11) and 2.098(12) $\AA$, while the Ag-O bond is 2.729(11) $\AA$. The $\mathrm{N}-\mathrm{Ag}-\mathrm{N}$ angle is $176.6(5)^{\circ}$. The $\mathrm{N}-\mathrm{Ag}-\mathrm{O}$ angles are in the range of 85.1(4)-95.0(5) ${ }^{\circ}$ (Table S1; supporting information).

In 4, there is the metal-organic subunit $\left[\mathrm{AgL}_{2}^{\mathrm{b}}\right]^{+}$. Adjacent $\mathrm{PMo}_{12}$ anions are linked by $\left[\mathrm{AgL}_{2}^{\mathrm{b}}\right]^{+}$to form a chain (Fig. 8). Between the adjacent chains, there are abundant hydrogen bonding interactions induced by carboxyl groups

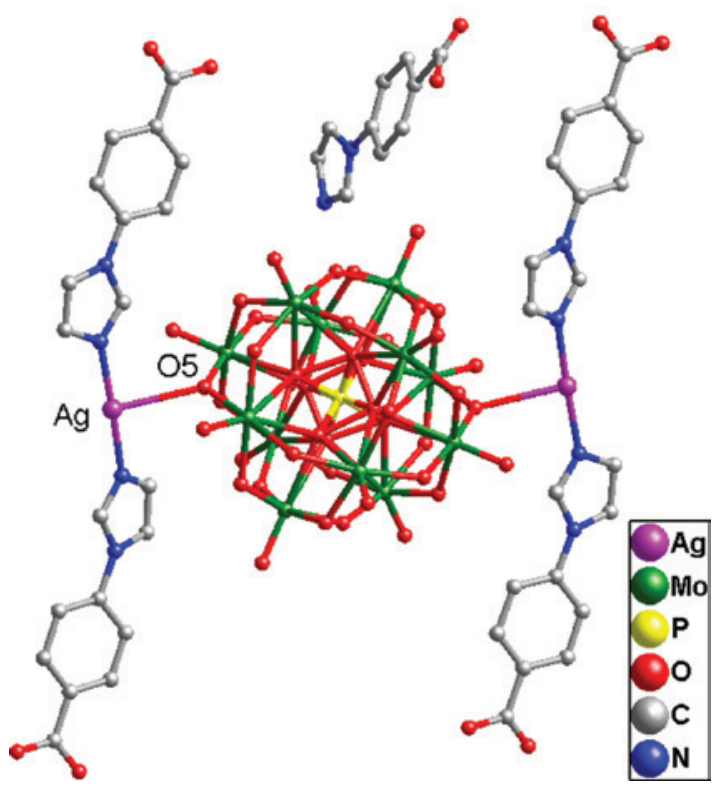

Fig. 7: Ball-and-stick view of the symmetric unit of 4. The hydrogen atoms are omitted for clarity.

$[023 \cdots 025=2.601(2) \AA$ and $024 \cdots 026=2.630(2) \AA]$ building this way a supramolecular layer (Fig. 9).

\subsection{Fourier transform infrared spectra}

Figure S3 (supporting information) shows the infrared spectra of the compounds 1-4. In the spectrum of $\mathbf{1}$, four characteristic bands appearing at 1057, 950, 873, and $791 \mathrm{~cm}^{-1}$ can be assigned to $v\left(\mathrm{P}-\mathrm{O}_{\mathrm{a}}\right), v\left(\mathrm{~W}-\mathrm{O}_{\mathrm{t}}\right), v\left(\mathrm{~W}-\mathrm{O}_{\mathrm{b}}\right)$, and $v\left(\mathrm{~W}-\mathrm{O}_{\mathrm{c}}\right)$, respectively. In the spectra of compounds $\mathbf{2}$ and $\mathbf{4}$ characteristic bands at 1062, 959, 878, and $796 \mathrm{~cm}^{-1}$ for 2 , and 1093, 957, 900, and $789 \mathrm{~cm}^{-1}$ for 4 are attributed to $v(\mathrm{P}-0)$, $v\left(\mathrm{Mo}-\mathrm{O}_{\mathrm{t}}\right), v\left(\mathrm{Mo}-\mathrm{O}_{\mathrm{b}}-\mathrm{Mo}\right)$, and $v\left(\mathrm{Mo}-\mathrm{O}_{\mathrm{c}}-\mathrm{Mo}\right)$. The characteristic vibration bands for $\left(\mathrm{P}-\mathrm{O}_{\mathrm{a}}\right),\left(\mathrm{W}-\mathrm{O}_{\mathrm{t}}\right)$, and $\left(\mathrm{W}-\mathrm{O}_{\mathrm{b} / \mathrm{c}}\right)$ appear respectively at $1099,966,921$, and $795 \mathrm{~cm}^{-1}$ for $\mathbf{3}$. Bands in

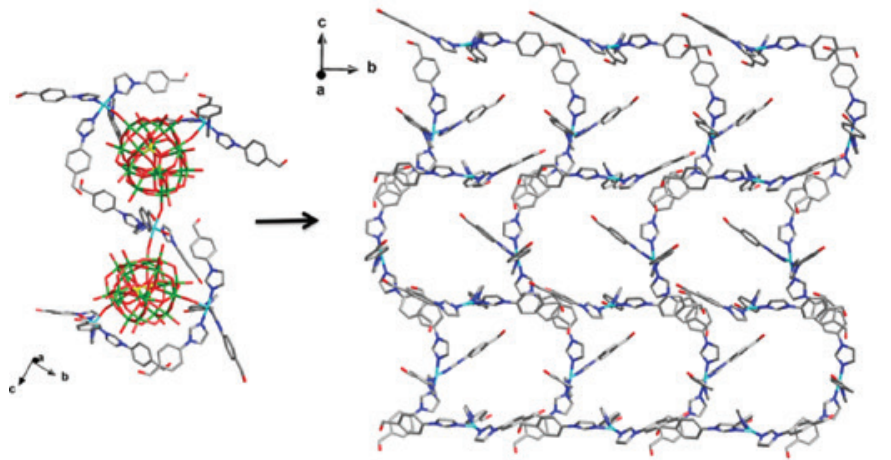

(a)
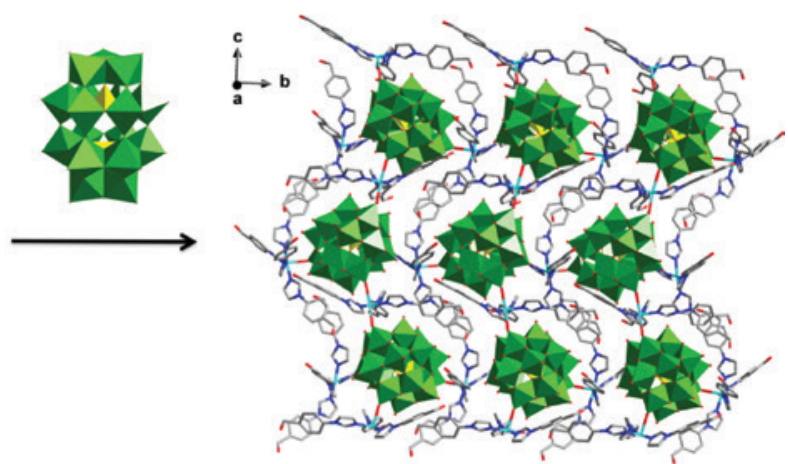

(c)

Fig. 6: (a) The "S"-type chain of 3. (b) and (c) The pane-like layer with the $P_{2} W_{18}$ anions embedded in the pane. 


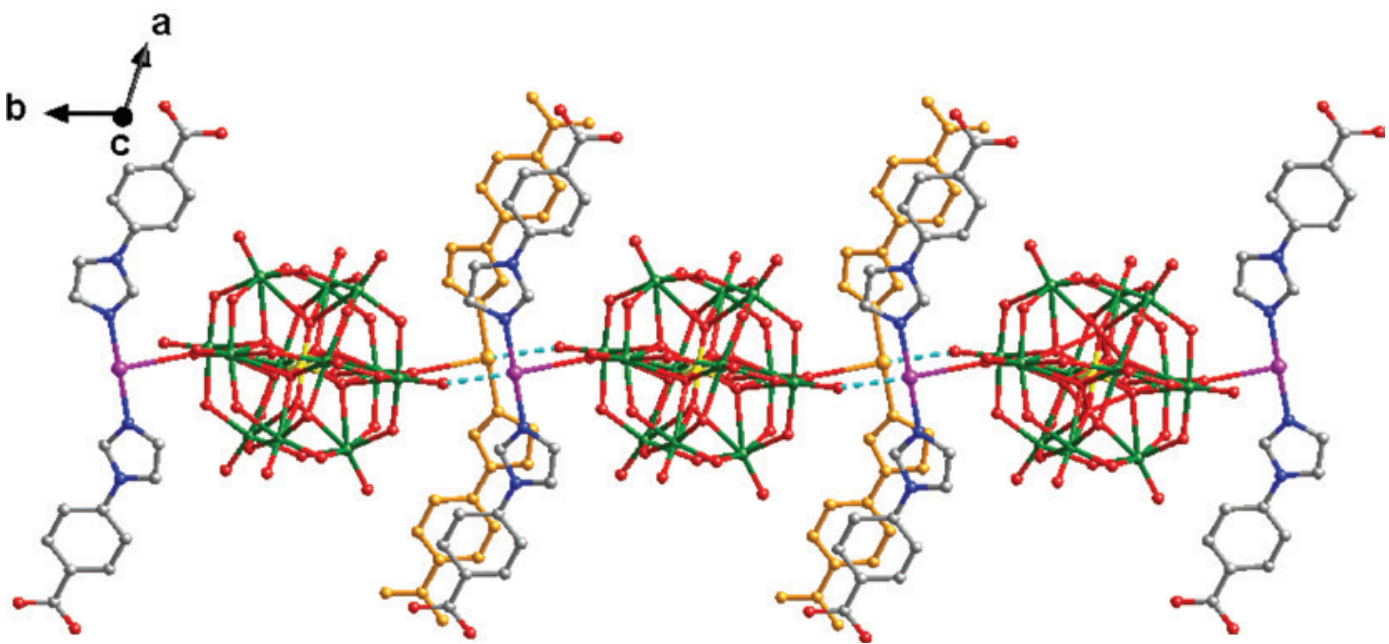

Fig. 8: The chain structure of 4.

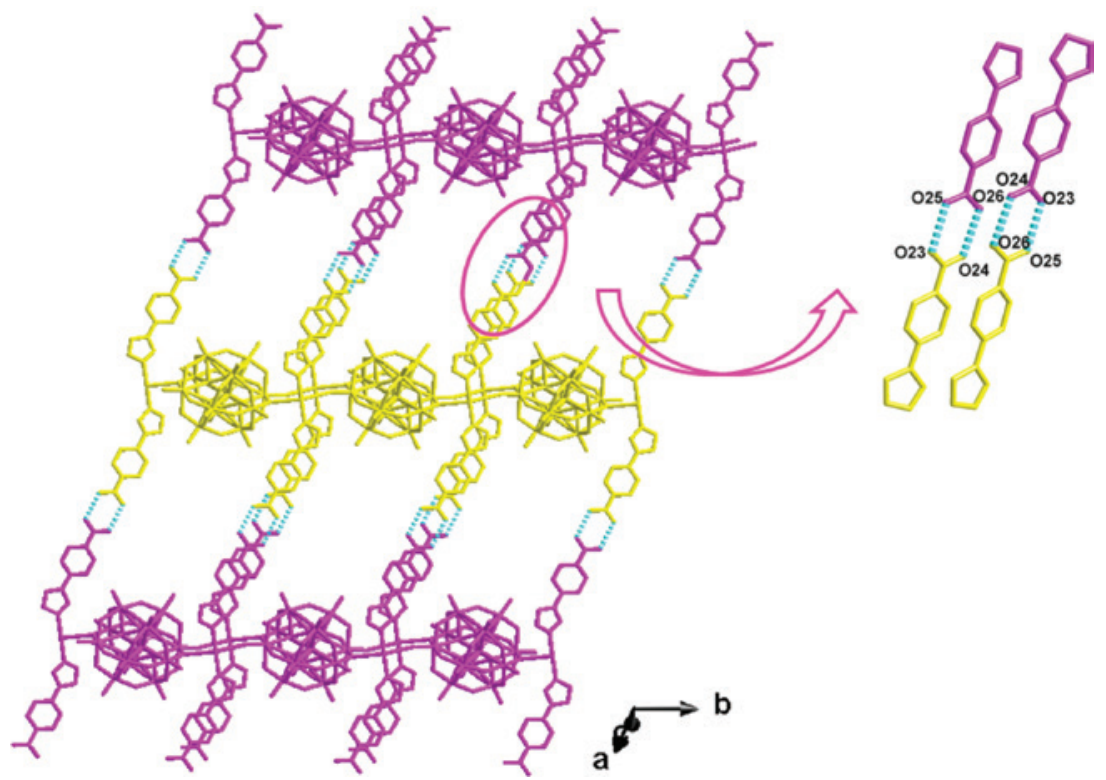

Fig. 9: The layer grid in the crystal structure of 4 linked through hydrogen bonding interactions between carboxyl groups.

the regions of $1694-1127 \mathrm{~cm}^{-1}$ for $1,1699-1166 \mathrm{~cm}^{-1}$ for $\mathbf{2}$, and $1699-1173 \mathrm{~cm}^{-1}$ for 3 are attributed to the $\mathbf{L}^{\mathrm{a}}$ ligand, while bands in the region of $1684-1173 \mathrm{~cm}^{-1}$ for 4 are attributed to the $\mathbf{L}^{\mathbf{b}}$ ligand, respectively.

\subsection{Voltammetric behavior and electrocatalytic activity}

We have studied the electrochemical properties of compounds 1-4 in $0.1 \mathrm{M} \mathrm{H}_{2} \mathrm{SO}_{4}+0.5 \mathrm{M} \mathrm{Na}_{2} \mathrm{SO}_{4}$ aqueous solution. The cyclic voltammograms of 1-carbon-paste electrodes (1$\mathrm{CPE}$ ) at different scan rates are presented in the potential range of +300 to $-800 \mathrm{mV}$. There are three reversible redox peaks I-I', II-II', and III-III' with the mean peak potentials $E_{1 / 2}=\left(E_{\mathrm{pa}}+E_{\mathrm{pc}}\right) / 2$ of $-223.5,-482$, and $-754.5 \mathrm{mV}$ (scan rate: $\left.60 \mathrm{mV} \cdot \mathrm{s}^{-1}\right)$. Redox peaks I-I' and II-II' correspond to two consecutive one-electron processes of $\mathrm{W}$ centers, while IIIIII' corresponds to a two-electron process [20]. The cyclic voltammograms of 2-CPE at different scan rates are presented in the potential range of +500 to $-220 \mathrm{mV}$. There are three reversible redox peaks I-I', II-II', and III-III' with the mean peak potentials $E_{1 / 2}=\left(E_{\mathrm{pa}}+E_{\mathrm{pc}}\right) / 2$ of $+330.5,+179.5$, and $-52.5 \mathrm{mV}$ (scan rate: $60 \mathrm{mV} \cdot \mathrm{s}^{-1}$ ), corresponding to three consecutive two-electron processes of the $\mathrm{PMo}_{12}$ anion [21]. The cyclic voltammograms of 3-CPE at different scan rates are presented in the potential range of +425 to $-820 \mathrm{mV}$. There also exist three reversible redox peaks II-II', III-III', 
and IV-IV' with the mean peak potentials $E_{1 / 2}=\left(E_{\mathrm{pa}}+E_{\mathrm{pc}}\right) / 2$ of -184.5(II-II'), -403.5(III-III'), -627(IV-IV') $\mathrm{mV}$ (scan rate: $60 \mathrm{mV} \cdot \mathrm{s}^{-1}$ ), corresponding to three consecutive twoelectron processes of the $\mathrm{P}_{2} \mathrm{~W}_{18}$ anion. Moreover, there also exists one irreversible anodic peak I with the potential of $+93 \mathrm{mV}$, which is assigned to the oxidation of the copper centers [22]. The cyclic voltammograms of 4-CPE at different scan rates are presented in the potential range of 550 to $-240 \mathrm{mV}$. There also exist three reversible redox peaks I-I', II-II' and III-III' with the mean peak potentials $E_{1 / 2}=\left(E_{\mathrm{pa}}+E_{\mathrm{pc}}\right) / 2$ of $+337.5,+190.5$, and $-43 \mathrm{mV}$ (scan rate: $\left.60 \mathrm{mV} \cdot \mathrm{s}^{-1}\right)$, corresponding to three consecutive twoelectron processes of the $\mathrm{PMo}_{12}$ anion [23] (Fig. 10). The peak potentials change gradually from 40 to $500 \mathrm{mV} \cdot \mathrm{s}^{-1}$ depending on the scan rates. The cathodic peak potentials shift towards the negative direction, while the corresponding anodic peak potentials to the positive direction. Up to $500 \mathrm{mV} \cdot \mathrm{s}^{-1}$, the peak currents are proportional to the scan rates (Fig. S4; supporting information), indicating that the redox processes of the 1-CPE to 4-CPE are surface-confined.

Figure 11 shows cyclic voltammograms for the electrocatalytic reduction of $\mathrm{KNO}_{2}$ at 1-CPE to 4-CPE. With the addition of $\mathrm{KNO}_{2}$, all the three reduction peak currents increase remarkably, while the corresponding oxidation peak currents gradually decrease. Figure 12 shows the electrocatalytic behavior of 1-CPE to 4-CPE in $0.1 \mathrm{M} \mathrm{H}_{2} \mathrm{SO}_{4}+0.5$ $\mathrm{M} \mathrm{Na}_{2} \mathrm{SO}_{4}+\mathrm{KBrO}_{3}$ aqueous solution. When we add potassium bromate to the aqueous solution, it can be clearly seen that while the corresponding oxidation peak currents are visibly decreased, all three reduction peak currents are gradually increased. These phenomena display that the three reductive species of $\mathrm{PMo}_{12}, \mathrm{PW}_{12}$, and $\mathrm{P}_{2} \mathrm{~W}_{18}$ possess electrocatalytic activities for the reduction of $\mathrm{NO}_{2}^{-}$ and $\mathrm{BrO}_{3}{ }^{-}$. Figure $\mathrm{S} 5$ (supporting information) shows the electrocatalytic behavior of 2-CPE to 4-CPE in $0.1 \mathrm{M} \mathrm{H}_{2} \mathrm{SO}_{4}+$ $0.5 \mathrm{M} \mathrm{Na}_{2} \mathrm{SO}_{4}+\mathrm{H}_{2} \mathrm{O}_{2}$ aqueous solution. When we add hydrogen peroxide to the aqueous solution, it can be clearly seen that while the corresponding oxidation peak currents are visibly decreased, all three reduction peak currents are gradually increased. The result shows that 1-CPE to 4-CPE exhibit good electrocatalytic activity for the reduction of nitrite, bromate, and hydrogen peroxide.

\subsection{Photocatalytic activity}

Under the ultra violet (UV) light irradiation, the photocatalytic activities of compounds $\mathbf{1 - 4}$ were studied in their
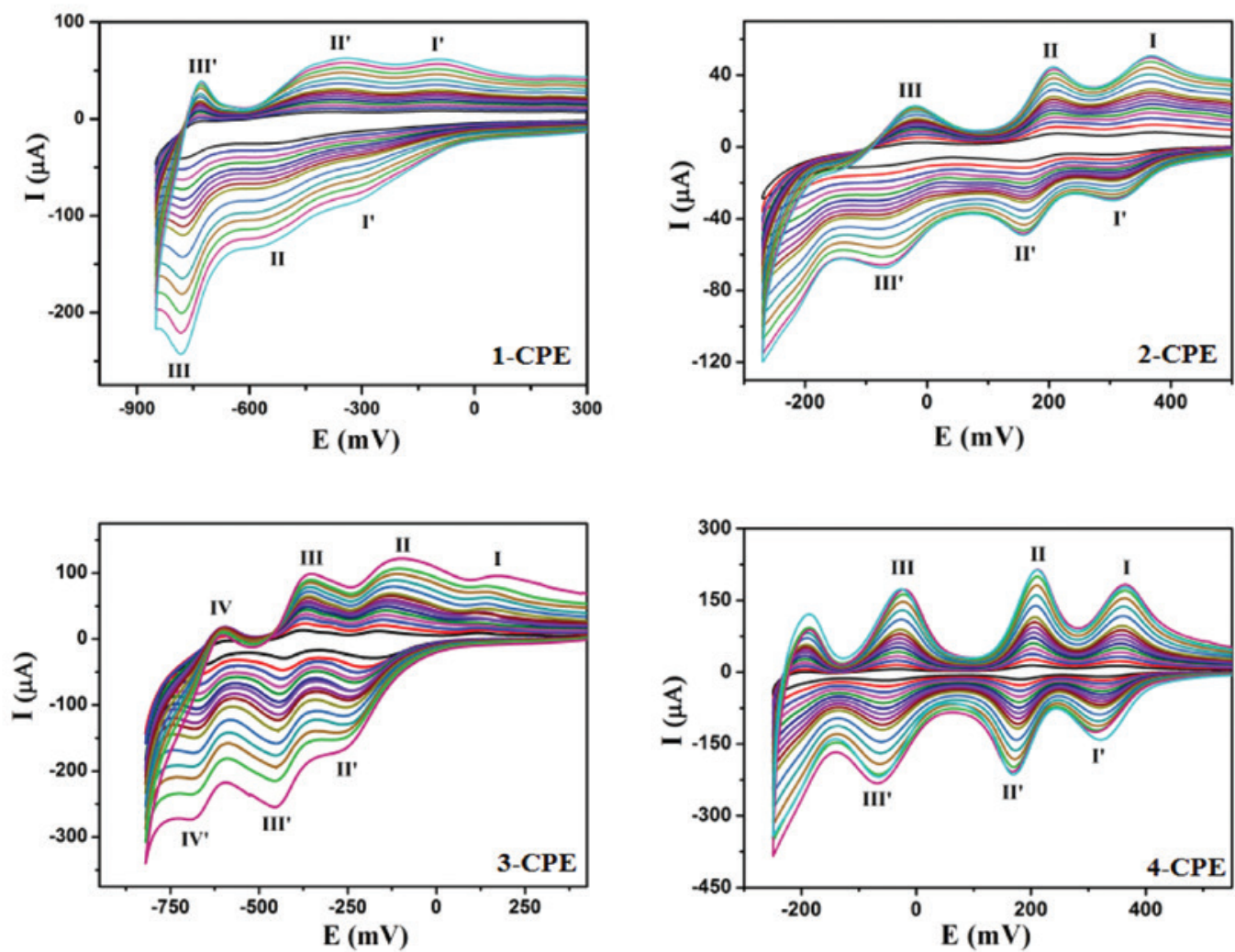

Fig. 10: The cyclic voltammograms of the carbon-paste electrodes 1-CPE, 2-CPE, 3-CPE, and 4-CPEs in $0.1 \mathrm{M} \mathrm{H}_{2} \mathrm{SO}_{4}+0.5 \mathrm{M} \mathrm{Na}_{2} \mathrm{SO}_{4}$ aqueous solution at different scan rates (from inner to outer: 40, 60, 80, 100, 120, 140, 160, 180, 200, 250, 300, 350, 400, 450, and $500 \mathrm{mV} \cdot \mathrm{s}^{-1}$, respectively). 

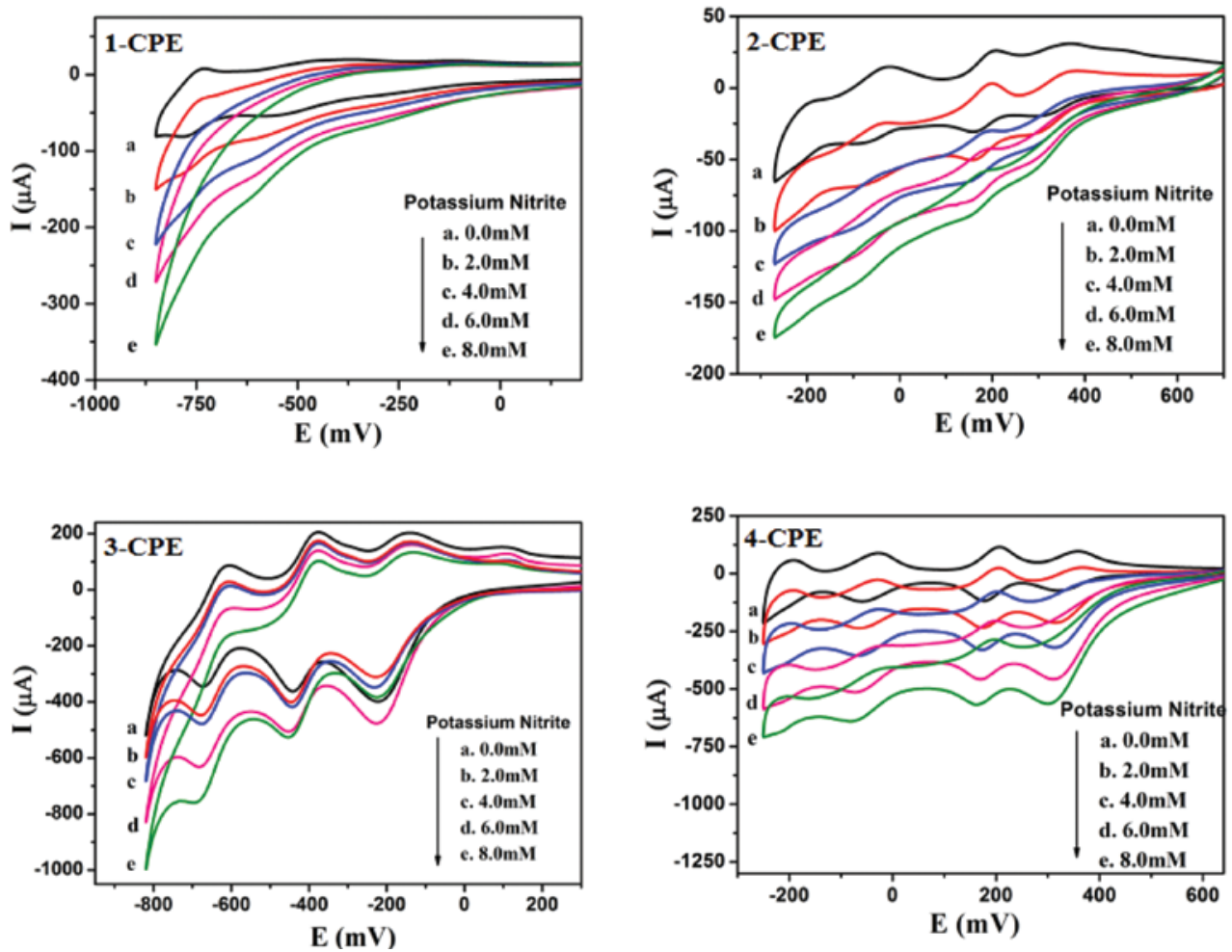

Fig. 11: Cyclic voltammograms of a 1-CPE to 4-CPE in $0.1 \mathrm{M} \mathrm{H}_{2} \mathrm{SO}_{4}+0.5 \mathrm{M} \mathrm{Na}_{2} \mathrm{SO}_{4}$ containing 0(a), 2.0(b), 4.0(c), 6.0(d), 8.0(e) mm potassium nitrite. Scan rate: $60 \mathrm{mV} \cdot \mathrm{s}^{-1}$.
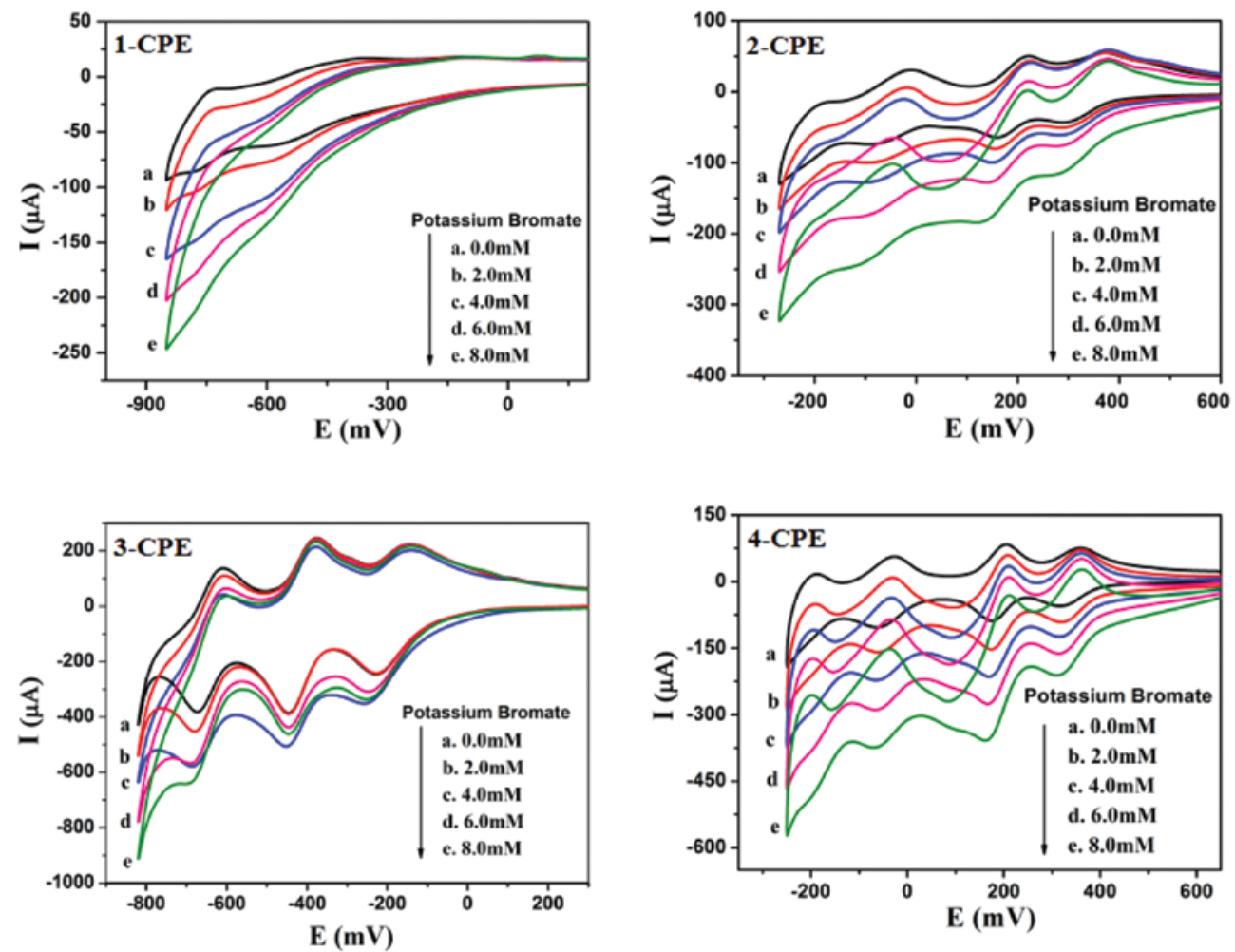

Fig. 12: Cyclic voltammograms of a 1-CPE to 4-CPE in $0.1 \mathrm{M} \mathrm{H}_{2} \mathrm{SO}_{4}+0.5 \mathrm{M} \mathrm{Na}_{2} \mathrm{SO}_{4}$ containing 0 (a), 2.0(b), 4.0(c), 6.0(d), 8.0(e) mM potassium bromate. Scan rate: $60 \mathrm{mV} \cdot \mathrm{s}^{-1}$. 
reaction with methylene blue $(\mathrm{MB})$ and rhodamine $\mathrm{B}(\mathrm{RhB})$ solutions. Steps are as follows: $100 \mathrm{mg}$ of compounds 1-4 were dispersed in $0.02 \mathrm{mmol} \cdot \mathrm{L}^{-1} \mathrm{MB} / \mathrm{RhB}$ aqueous solution $(90 \mathrm{~mL})$. It is necessary to stir magnetically for about $15 \mathrm{~min}$ in the dark to make sure that the solution is equilibrated. The mixed solution was stirred continuously under a UV Hg lamp. After intervals of $30 \mathrm{~min}, 5.0 \mathrm{~mL}$ samples were taken out for analysis in a Lambda 750 UV/VIS/ NIR spectrophotometer. As shown in Fig. S6 (supporting information), we can see clearly that when increasing the reaction time, the percentage of $\mathrm{MB}$ degradation photocatalyzed by $\mathbf{1 - 4}$ is increased. The conversions of $\mathrm{MB}$ are $33 \%$ for $\mathbf{1}, 32 \%$ for $\mathbf{2}, 31 \%$ for $\mathbf{3}$, and $25 \%$ for $\mathbf{4}$ after $120 \mathrm{~min}$. Figure S7 (supporting information) shows the photocatalytic degradation of $\mathrm{RhB}$ with the conversions of $36 \%$ for $\mathbf{1}$, $31 \%$ for $\mathbf{2}, 29 \%$ for 3 , and $30 \%$ for 4 after $120 \mathrm{~min}$.

\section{Conclusions}

In this work, four POM-based compounds with different iminazole derivatives were synthesized and characterized. The ligands $\mathbf{L}^{\mathbf{a}}$ and $\mathbf{L}^{\mathbf{b}}$ contain $\mathrm{N}$ and $\mathrm{O}$ donor atoms. In compounds 1-4, the $\mathrm{N}$ donors of the ligands coordinate with TM ions and $\mathrm{O}$ atoms offer abundant hydrogen bonding interactions. Compound $\mathbf{1}$ shows a supramolecular layer. Introducing different POM anions to the system $\mathrm{Cu}^{2+} / \mathbf{L}^{\mathrm{a}}$ induces distinct structures of compounds 1-3: different discrete structures of $\mathbf{1}$ and $\mathbf{2}$ and a 2D structure of $\mathbf{3}$. By changing the ligand $\mathbf{L}^{\mathrm{a}}$ to $\mathbf{L}^{\mathbf{b}}$, a supramolecular layer consisted by chains of compound $\mathbf{4}$ is formed. These four compounds exhibit good electrocatalytic activities for the reduction of nitrite, bromate, and hydrogen peroxide. Compounds 1-4 also show photocatalytic activities for MB and RhB. Further studies on exploring other mixed donor ligands are underway to construct POM-based compounds with intriguing properties.

\section{Experimental section}

\subsection{Materials and methods}

All reagents were of analytical grade and were used as received from commercial sources without further purification. Elemental analyses (C, H, and N) were performed using a Perkin-Elmer $2400 \mathrm{CHN}$ elemental analyzer (PerkinElmer, Waltham, MA, USA). The IR spectra were obtained using a Magna FT-IR 560 spectrometer (Thermo Fisher Nicolet, Waltham, MA, USA) with KBr pellets in the 400$4000 \mathrm{~cm}^{-1}$ region. Electrochemical measurements were performed with a CHI 440 electrochemical workstation (Shanghai Chenhua Instrument Co., Ltd.). A conventional three-electrode system was used. A saturated calomel electrode (SCE) was used as a reference electrode, and a Pt wire as a counter electrode. CPEs were used as the working electrodes, a SCE was used as a reference electrode, and a Pt wire was used as the counter electrode. UV/Vis absorption spectra were obtained using a UV-1801 spectrophotometer [Rayleigh Analytical Instrument (Beijing) Co., Ltd.]. The organic proligands, POM anions, metal salts and solvents were purchased from commercial sources [analytically pure, Nine-Dinn Chemistry (Shanghai) Co., Ltd.].

\subsection{Synthesis}

\subsection{1 $\left[\mathrm{Cu}_{2} \mathrm{~L}_{4}^{\mathrm{a}}\left(\mathrm{HPW}_{12} \mathrm{O}_{40}\right)\right](1)$}

A mixture of $\mathrm{H}_{3} \mathrm{PW}_{12} \mathrm{O}_{40} \cdot 24 \mathrm{H}_{2} \mathrm{O}(0.08 \mathrm{~g}, 0.024 \mathrm{mmol})$, $\mathrm{Cu}\left(\mathrm{CH}_{3} \mathrm{COO}\right)_{2} \cdot 2 \mathrm{H}_{2} \mathrm{O}(0.02 \mathrm{~g}, 0.09 \mathrm{mmol})$, and $\mathbf{L}^{\mathrm{a}}(0.02 \mathrm{~g}$, $0.117 \mathrm{mmol}$ ) was dissolved in $10 \mathrm{~mL}$ of distilled water at room temperature. The $\mathrm{pH}$ of the mixture was adjusted to about 3.5 with $1.0 \mathrm{M} \mathrm{HNO}_{3}$, the resulting suspension was heated in a teflon-lined autoclave at $160^{\circ} \mathrm{C}$ and autogeneous pressure for 4 days. After slow cooling to room temperature, red block crystals were filtered and washed with distilled water (39\% yield of $\mathbf{1}$ based on $\mathrm{W}$ ); anal. calcd. for $\mathrm{C}_{40} \mathrm{H}_{33} \mathrm{Cu}_{2} \mathrm{~N}_{8} \mathrm{O}_{44} \mathrm{PW}_{12}$ (3693): C 13.00, $\mathrm{H}$ 0.90, $\mathrm{N}$ 3.03; found $\mathrm{C}$ 12.95, $\mathrm{H} 0.93, \mathrm{~N} 3.09 \%$.

\subsection{2 $\left[\mathrm{CuL}_{4}^{\mathrm{a}}{ }_{4}\left(\mathrm{H}_{2} \mathrm{O}\right)_{2}\left(\mathrm{HPMO}_{12} \mathrm{O}_{40}\right)\right](2)$}

A mixture of $\mathrm{H}_{3} \mathrm{PMo}_{12} \mathrm{O}_{4}(0.08 \mathrm{~g}, 0.044 \mathrm{mmol})$, $\mathrm{Cu}\left(\mathrm{CH}_{3} \mathrm{COO}\right)_{2} \cdot 2 \mathrm{H}_{2} \mathrm{O}(0.02 \mathrm{~g}, 0.09 \mathrm{mmol})$, and $\mathbf{L}^{\mathrm{a}}(0.02 \mathrm{~g}$, $0.117 \mathrm{mmol}$ ) was dissolved in $10 \mathrm{~mL}$ of distilled water at room temperature. The $\mathrm{pH}$ of the mixture was adjusted to about 3.4 with $1.0 \mathrm{M} \mathrm{HNO}_{3}$, the resulting suspension was heated in a teflon-lined autoclave at $160^{\circ} \mathrm{C}$ and autogeneous pressure for 4 days. Red block crystals were filtered and washed with distilled water (40\% yield of 2 based on Mo); anal. calcd. for $\mathrm{C}_{40} \mathrm{H}_{37} \mathrm{CuMo}_{12} \mathrm{~N}_{8} \mathrm{O}_{46} \mathrm{P}$ (2612): $\mathrm{C} 18.39, \mathrm{H}$ 1.43, N 4.29; found C 18.23, $\mathrm{H} 1.32$, N 4.33\%.

\subsection{3 $\left[\mathrm{Cu}_{2} \mathrm{~L}_{7}{ }_{7}\left(\mathrm{H}_{2} \mathrm{O}\right)\left(\mathrm{H}_{2} \mathrm{P}_{2} \mathrm{~W}_{18} \mathrm{O}_{62}\right)\right] \cdot \mathrm{L}^{\mathrm{a}}(3)$}

A mixture of $\mathrm{H}_{6} \mathrm{P}_{2} \mathrm{~W}_{18} \mathrm{O}_{62} \cdot 6 \mathrm{H}_{2} \mathrm{O}(0.08 \mathrm{~g}, 0.018 \mathrm{mmol})$, $\mathrm{Cu}\left(\mathrm{CH}_{3} \mathrm{COO}\right)_{2} \cdot 2 \mathrm{H}_{2} \mathrm{O}(0.02 \mathrm{~g}, 0.09 \mathrm{mmol})$, and $\mathbf{L}^{\mathrm{a}}(0.02 \mathrm{~g}$, $0.117 \mathrm{mmol}$ ) was dissolved in $10 \mathrm{~mL}$ of distilled water at room temperature. The $\mathrm{pH}$ of the mixture was adjusted to about 3.7 with $1.0 \mathrm{M} \mathrm{HNO}_{3}$, the resulting suspension was 
heated in a teflon-lined autoclave at $160^{\circ} \mathrm{C}$ and autogeneous pressure for 4 days. Red block crystals were filtered and washed with distilled water (41\% yield of 3 based on W); anal. calcd. for $\mathrm{C}_{80} \mathrm{H}_{68} \mathrm{Cu}_{2} \mathrm{~N}_{16} \mathrm{O}_{71} \mathrm{P}_{2} \mathrm{~W}_{18}$ (5887): $\mathrm{C} 16.31, \mathrm{H}$ 1.16, N 3.81; found C 16.39, H 1.09, N 3.78\%.

\subsection{4 $\left[\mathrm{Ag}_{2}\left(\mathrm{~L}_{4}^{\mathrm{b}}\right)\left(\mathrm{HPMo}_{12} \mathrm{O}_{40}\right)\right] \cdot \mathrm{L}^{\mathrm{b}} \cdot \mathrm{H}_{2} \mathrm{O}(4)$}

A mixture of $\mathrm{H}_{3} \mathrm{PMo}_{12} \mathrm{O}_{4}(0.08 \mathrm{~g}, 0.044 \mathrm{mmol}), \mathrm{AgNO}_{3}(0.1 \mathrm{~g}$, $0.589 \mathrm{mmol})$, and $\mathbf{L}^{\mathbf{b}}(0.02 \mathrm{~g}, 0.113 \mathrm{mmol})$ were dissolved in $10 \mathrm{~mL}$ of distilled water at room temperature. The $\mathrm{pH}$ of the mixture was adjusted to about 1.1 with $1.0 \mathrm{M} \mathrm{HNO}_{3}$, and the suspension was put into a teflon-lined autoclave and kept under autogeneous pressure at $160^{\circ} \mathrm{C}$ for 4 days. After slow cooling to room temperature, yellow block crystals were filtered and washed with distilled water (32\% yield of $\mathbf{4}$ based on Mo); anal. calcd. for $\mathrm{C}_{50} \mathrm{H}_{43} \mathrm{Ag}_{2} \mathrm{Mo}_{12} \mathrm{~N}_{10} \mathrm{O}_{51} \mathrm{P}$ (2998): C 20.03, H 1.45, N 4.67; found C 20.89, H 1.50, N 4.98\%.

\subsection{X-ray crystallography}

X-ray diffraction data were collected using a Bruker Smart Apex II (Bruker Analytical Instruments, Germany) POM anions diffractometer with $\operatorname{Mo} K \alpha$ radiation $(\lambda=0.71073 \AA)$ at $T=293 \mathrm{~K}$. All the structures were solved by direct methods and refined on $F^{2}$ by full-matrix least-squares methods using the SHELXTL package [24-26]. For the compounds, all the hydrogen atoms attached to carbon atoms were generated geometrically, while the hydrogen atoms attached to water molecules were not located but were included in the structure factor calculations.

Several restrains had to be applied for the anisotropic displacement parameters (RIGU and ISOR) to get a better refining model. The quality of the data of the structure determination of $\mathbf{1}$ was not good enough to identify all the interstitial solvent molecules. The crystal structure of $\mathbf{3}$ contained large voids. The solvent molecules and the ions located in the void could not be identified due to disorder with substantial residual electron density. Therefore, the routine SQUEEZE in PLATON [27] was used to remove this electron density in the structures of $\mathbf{1}$ and $\mathbf{3}$.

In the crystal structure of $\mathbf{2}$, the free, uncoordinated ligand was found to be disordered, In the crystal structure of 4, the free, uncoordinated ligand and a water molecule nearby were found to be disordered and refined with a split-atom model.

The crystal data and structures refinement data for 1-4 are given in Table 2. Selected bond lengths and angles of 1-4 are listed in Table S1 (supporting information).

Table 2: Crystal data and numbers pertinent to data collection and structure refinement of compounds 1-4.

\begin{tabular}{|c|c|c|c|c|}
\hline & 1 & 2 & 3 & 4 \\
\hline $\begin{array}{l}\text { Formula } \\
F w, \mathrm{~g} \mathrm{~cm}^{-3}\end{array}$ & $\begin{array}{l}\mathrm{C}_{40} \mathrm{H}_{33} \mathrm{Cu}_{2} \mathrm{~N}_{8} \mathrm{O}_{44} \mathrm{PW}_{12} \\
3693\end{array}$ & $\begin{array}{l}\mathrm{C}_{40} \mathrm{H}_{37} \mathrm{CuMo}_{12} \mathrm{~N}_{8} \mathrm{O}_{46} \mathrm{P} \\
2612\end{array}$ & $\begin{array}{l}\mathrm{C}_{80} \mathrm{H}_{68} \mathrm{Cu}_{2} \mathrm{~N}_{16} \mathrm{O}_{71} \mathrm{P}_{2} \mathrm{~W}_{18} \\
5887\end{array}$ & $\begin{array}{l}\mathrm{C}_{50} \mathrm{H}_{43} \mathrm{Ag}_{2} \mathrm{Mo}_{12} \mathrm{~N}_{10} \mathrm{O}_{51} \mathrm{P} \\
2998\end{array}$ \\
\hline Temperature, $\mathrm{K}$ & $293(2)$ & $293(2)$ & $293(2)$ & $293(2)$ \\
\hline Crystal system & Monoclinic & Triclinic & Monoclinic & Triclinic \\
\hline Space group & $C 2 / c$ & $P \overline{1}$ & $C 2 / c$ & $P \overline{1}$ \\
\hline$a, \AA$ & 19.8894(19) & $10.6221(6)$ & $63.223(5)$ & $11.3410(6)$ \\
\hline$b, \AA$ & 14.7883(19) & $13.4807(8)$ & $14.927(5)$ & $13.9934(7)$ \\
\hline$c, \AA$ & $25.187(3)$ & $14.8891(8)$ & $27.085(5)$ & $14.5129(7)$ \\
\hline$\alpha$, deg & 90 & $70.096(1)$ & 90 & $93.879(1)$ \\
\hline$\beta$, deg & $93.917(3)$ & $80.188(1)$ & $90.979(5)$ & $107.007(1)$ \\
\hline$\gamma, \operatorname{deg}$ & 90 & $88.117(1)$ & 90 & 104.821(1) \\
\hline$V, \AA^{3}$ & $7390.8(14)$ & 1974.61(19) & 25557.2(15) & 2103.75(18) \\
\hline$Z$ & 4 & 1 & 8 & 1 \\
\hline$D_{c}, \mathrm{~g} \cdot \mathrm{cm}^{-3}$ & 3.32 & 2.195 & 3.06 & 2.37 \\
\hline$\mu, \mathrm{mm}^{-1}$ & 19.3 & 2.2 & 16.6 & 2.3 \\
\hline$F(000), e$ & 6564 & 1248 & 21176 & 1434 \\
\hline$\Theta$ range, deg & $1.62-25.06$ & $1.61-28.28$ & $1.40-25.68$ & $1.96-26.37$ \\
\hline Refs. measured & 20417 & 12422 & 76688 & 11998 \\
\hline Refs. unique $/ R_{\text {int }}$ & $6526 / 0.0983$ & $9016 / 0.0138$ & $24266 / 0.0838$ & $8454 / 0.0159$ \\
\hline Ref. parameters & 460 & 517 & 1712 & 739 \\
\hline$R 1^{\mathrm{a}}[I>2 \sigma(I)]$ & 0.0793 & 0.0406 & 0.0438 & 0.0977 \\
\hline$w R 2^{\mathrm{b}}$ (all data) & 0.2370 & 0.0921 & 0.1026 & 0.2061 \\
\hline $\mathrm{GoF}^{\mathrm{c}}$ on $F^{2}$ & 1.037 & 1.025 & 1.003 & 1.289 \\
\hline$\Delta \rho_{\text {fin }}(\max / \min ), e \AA^{-3}$ & $4.358 /-2.891$ & $1.249 /-1.190$ & $2.582 /-2.579$ & $1.758 /-1.830$ \\
\hline
\end{tabular}

${ }^{\mathrm{a}} R 1=\Sigma|| F_{0}|-| F_{\mathrm{c}}|| / \Sigma\left|F_{0}\right| ;{ }^{\mathrm{b}} W R 2=\left[\Sigma w\left(F_{0}^{2}-F_{\mathrm{c}}^{2}\right)^{2} / \Sigma w\left(F_{0}^{2}\right)^{2}\right]^{1 / 2}, w=\left[\sigma^{2}\left(F_{0}^{2}\right)+(\mathrm{A} P)^{2}+\mathrm{BP}\right]^{-1}$, where $P=\left(\operatorname{Max}\left(F_{0}^{2}, 0\right)+2 F_{\mathrm{c}}^{2}\right) / 3 ;{ }^{\mathrm{c}} \mathrm{GoF}=S=\left[\Sigma w\left(F_{0}^{2}-F_{c}^{2}\right)^{2} /\right.$ $\left.\left(n_{\text {obs }}-n_{\text {param }}\right)\right]^{1 / 2}$. 
Table S2 (supporting information) summarizes hydrogen bond lengths for compounds 1-4.

CCDC 1553303, 1550048, 1550049, and 1550479 contain the supplementary crystallographic data for this paper. These data can be obtained free of charge from The Cambridge Crystallographic Data Centre via www.ccdc.cam. ac.uk/data_request/cif.

\subsection{Preparation of bulk-modified CPEs of compounds 1 to 4}

The electrode of compound $\mathbf{1}$ modified with CPE (1-CPE) was made as follows: $90 \mathrm{mg}$ of graphite powder and $8 \mathrm{mg}$ of $\mathbf{1}$ were mixed and ground together by an agate mortar and pestle to achieve a uniform mixture, and then $0.1 \mathrm{~mL}$ of Nujol was added with stirring. The homogenized mixture was packed into a glass tube with a $1.5 \mathrm{~mm}$ inner diameter, and the tube surface was wiped with paper. Electrical contact was established with a copper rod through the back of the electrode. In a similar manner, 2$\mathrm{CPE}$, 3-CPE, and 4-CPE were made with compounds $\mathbf{2}, \mathbf{3}$, and 4, respectively.

\section{Supporting information}

The 2D structures, IR spectra cyclic voltammograms, selected bond distances, and angles of compounds 1-4 and other supporting data associated with this article can be found in the online version (DOI: 10.1515/znb-20180067).

Acknowledgments: Financial supports of this research were provided by the National Natural Science Foundation of China (No. 21571023, 21101015, 21401010, and 21471021) and Program of the Innovative Research Team in University of Liaoning Province (LT2012020).

\section{References}

[1] P. C. Yin, B. Wu, E. Mamontov, L. L. Daemen, Y. Q. Cheng, T. Li, S. Seifert, K. L. Hong, P. V. Bonnesen, J. K. Keum, A. J. RamirezCuesta, J. Am. Chem. Soc. 2016, 138, 2638.
[2] C. Zhang, W. B. Bu, D. L. Ni, C. J. Zuo, C. Cheng, Q. Li, L. L. Zhang, Z. Wang, J. L. Shi, J. Am. Chem. Soc. 2016, 138, 8156.

[3] P. Huang, X. G. Han, X. L. Li, C. Qin, X. L. Wang, Z. M. Su, Cryst. Eng. Commun. 2016, 18, 8722.

[4] J. J. Walsha, A. M. Bond, R. J. Forster, T. E. Keyes, Coord. Chem. Rev. 2015, 306, 217.

[5] X. Wang, R. Zhang, A. X. Tian, X. L. Wang, Z. Anorg. Allg. Chem. 2015, 641, 1718.

[6] S. Taleghani, M. Mirzaei, H. Eshtiagh-Hosseini, A. Frontera, Coord. Chem. Rev. 2016, 309, 84.

[7] E. L. Zhou, C. Qin, X. L. Wang, K. Z. Shao, Z. M. Su, Cryst. Eng. Commun. 2016, 18, 6370.

[8] X. Li, Y. Chen, X. L. Chi, Y. C. Xu, Q. Yang, H. Y. Zhang, J. L. Zhang, D. R. Xiao, Inorg. Chim. Acta 2015, 437, 59.

[9] H. Sartzi, H. N. Miras, L. Vilà-Nadal, D.-L. Long, L. Cronin, Angew. Chem. Int. Ed. 2015, 54, 15488.

[10] A. X. Tian, Z. G. Han, J. Peng, J. Q. Sha, J. L. Zhai, P. P. Zhang, J. Chen, H. S. Liu, Z. Anorg. Allg. Chem. 2007, 633, 2730.

[11] Y. Q. Jiao, C. Qin, H. Y. Zang, W. C. Chen, C. G. Wang, T. T. Zheng, K. Z. Shao, Z. M. Su, Cryst. Eng. Commun. 2015, 17, 2176.

[12] J. Q. Sha, J. Peng, A. X. Tian, H. S. Liu, J. Chen, P. P. Zhang, Z. M. Su, Cryst. Growth Des. 2007, 7, 2535.

[13] A. X. Tian, Y. L. Ning, Y. Yang, X. Hou, J. Ying, G. C. Liu, J. W. Zhang, X. L. Wang, Dalton Trans. 2015, 44, 16486.

[14] J. Ying, N. Sun, L. Yan, X. L. Lin, Y. J. Liu, Y. Yang, R. Xiao, A. X. Tian, Z. Anorg. Allg. Chem. 2014, 640, 968.

[15] A. X. Tian, Y. Tian, Y. L. Ning, X. Hou, H. P. Ni, X. B. Ji, Dalton Trans. 2016, 45, 13925.

[16] M. J. Cao, Y. K. Li, P. P. Sun, C. Y. Zhang, J. Wang, Q. Y. Li, G. W. Yang, Z. Anorg. Allg. Chem. 2016, 642, 1218.

[17] X. L. Wang, J. Luan, F. F. Sui, H. Y. Lin, G. C. Liu, C. Xu, Cryst. Growth Des. 2013, 13, 3561.

[18] S. B. Li, H. Y. Ma, H. J. Pang, L. Zhang, Cryst. Growth Des. 2014, 14, 4450.

[19] I. D. Brown, D. Altermatt, Acta Crystallogr. 1985, B41, 244.

[20] X. L. Wang, D. Zhao, A. X. Tian, J. Ying, Cryst. Eng .Commun. 2013, 15, 4516.

[21] Y. H. Ding, J. Peng, H. Y. Lu, Y. Yuan, S. U. Khan, RSC Adv. 2016, 6, 81085 .

[22] A. X. Tian, Y. L. Ning, H. P. Ni, X. Hou, R. Xiao, J. Ying, Z. Naturforsch. 2016, 71, 1125.

[23] X. L. Wang, R. Zhang, X. Wang, H. Y. Lin, G. C. Liu, Inorg. Chem. 2016, 55, 6384.

[24] G. M. Sheldrick, ShelXtL (version 6), Bruker AXS Inc., Madison, WI, USA, 2001.

[25] G. M. Sheldrick, Acta Crystallogr. 1990, A46, 467.

[26] G. M. Sheldrick, Acta Crystallogr. 2008, A64, 112.

[27] A. L. Spek, J. Appl. Crystallogr. 2003, 36, 7.

Supplementary Material: The online version of this article offers supplementary material (https://doi.org/10.1515/znb-2018-0067). 